\title{
Platforms in the Sharing Economy: Does Business Strategy Determine Platform Structure?
}

\author{
Eric K. Clemons \\ The Wharton School \\ clemons@upenn.edu
}

\author{
Ioanna Constantiou \\ Copenhagen B School \\ ic.digi@cbs.dk
}

\author{
Attila Marton \\ Copenhagen B School \\ am.digi@cbs.dk
}

\author{
Tuunainen Virpi \\ Aalto University \\ virpi.tuunainen@aalto.fi
}

\begin{abstract}
Sharing economy businesses are increasingly important, but the relationships between their strategies and their platforms' structure has received insufficient attention. To address this gap, we develop testable hypotheses building on following expectations. 1) Sharing economy businesses are attacking mature markets; 2) most sharing economy businesses follow one of Porter's two basic strategies, seeking a price advantage or a differentiation advantage; and 3) platforms that support differentiation-based strategies must provide more information to their users than platforms that support cost-based strategies. We located a database of 100 investment-grade sharing economy businesses to test our hypotheses. Our hypotheses received strong support from this database.
\end{abstract}

\section{Introduction}

The recent impact of sharing economy businesses cannot be missed. You can now share everything you own with a total stranger, from your car and your spare bedroom to a home-prepared dinner around the world. The sharing economy allows you to share physical durables, of course; the best-known examples, Uber and Airbnb, allow you to share the use of your car or the use of your home, for a fee. A broader view of the sharing economy would include what we term the participatory economy [24]. Well-known platforms like TaskRabbit involve creating a spot market for individuals willing and able to perform simple tasks. While this does not involve sharing durable physical goods in the same ways that Uber and Airbnb do, we believe that these participatory economy platforms can be considered examples of the sharing economy.

Platforms vary enormously in the amount of information that they present to individual users, in the search facilities they offer users to identify service providers, and in the degree of choice that they allow individual users in selecting specific service providers. We believe that those differences are not random, and that differences in the levels of information provided, in the filters for selection, and in the degree of choice supported all reflect underlying differences among the strategies pursued by the platform operators.

We chose to study this topic for several reasons. First, platform-based business is increasingly important. Although the impact of platform-based business is now universally acknowledged, there is as yet no sound and generally accepted theory that will predict when platforms will succeed or how platforms should be structured to facilitate adoption and success. That is not to say we do not understand user interface considerations for platform design when we fully understand the functions to be supported. Rather, it suggests that we do not yet understand what information is required, what degree of trust is required, and what degree of user choice is required to ensure success in a platform-based business.

Second, the sharing economy is increasingly important. Major manufacturers need to understand when their products are sharable and how that will affect demand. Traditional intermediaries need to understand when their owned-inventory model represents higher cost, or more limited choice, and is unsustainable. In order to assess the chances for future success, entrepreneurs and investors need to understand when it is possible, even easy, to attack an existing market, and when it is difficult. It would be extremely useful to have a strong predictive theory for assessing the potential success for sharing economy platform-based businesses (SEPBs).

Moreover, it is now possible to perform at least some statistical analyses on sharing economy platform-based businesses. There are now well over 100 SEPBs that have received rounds of private equity funding. Many of these are reviewed in a range of publications, and there is financial data or investment history data available for many of them as well.

To address the research gap discussed above, we started with an in-depth analysis of four well-known, well-funded, widely used, and generally successful SEPBs. Among these four SEPBs, we observed patterns for which we believe there are sound theoretical explanations. We used abductive reasoning and these explanations to generate our hypotheses. The process of hypothesis generation is described in more detail in the methodology section. The hypothesis examine 
relationships between the strategy of the SEPBs and the structure of their websites, and between the strategy of the SEPB and the structure of the marketplace they are seeking to enter. We call these internal and external consistency.

In this paper, we test our hypotheses using a data set of SEPBs. The data set was selected by Drew Mentock, writing for Money Nomad, an online journal (http://www.moneynomad.com/about) aimed at investors who hope to succeed with strategies involving online businesses. Since this is not an academic journal, we did not base any part of our analysis upon the content of the article; we merely used the article to provide a list of websites. Since this data set was compiled based on the Mentock's assessment of the SEPBs attractiveness to investors, it should represent a sample of businesses with above average chances of success. That is, we are studying businesses that are considered to have made better than average decisions in design and in strategy. Since this data set was selected by others, it should be free of the sort of sample bias that might have been introduced, even unintentionally, if we were allowed to select those candidate businesses we choose to study. We show that successful SEPBs do share several characteristics in common, including attacking newly vulnerable markets and matching their website structure to their strategies.

\section{Literature Review}

In an era of information-based micro segmentation, Porter's generic business strategies of cost-based or differentiation-based leadership [21, 20] no longer represent a binary classification nor is each company represented by one or the other of the two alternatives. Individual products can be located in any position on the continuum between cost and differentiation that is economically feasible for production. Multi-product firms can embrace a complex set of positions on this continuum.

Still, it seems likely that any single platform-based offering will represent either a focus on cost or a focus on differentiation. This seems plausible at this time, in part because the sharing economy is newer than other markets for products and services, and less crowded, so that simpler strategies may remain effective. Larger SEPBs over time may develop a portfolio of offerings, which may embrace a range of strategies. With the assumption that start-up SEPBs can be classified as either competing with a focus on cost or with a focus on differentiation, we use Porter's two generic strategies to represent one dimension of our analysis of digital platforms. We classify strategies of the SEPBs using Porter's classification, and study to understand which of these strategies determine the structures of these firms. Since the classification produced statistically significant results, we deem it acceptable at this stage of development of the sharing economy.

There is a large literature in corporate strategy and organizational design, going back to Chandler [5], that argues that the structure of a firm is determined by its strategy. The earliest examples suggest that a firm with a multi-business strategy (like Sears \& Roebuck) or a multi-product strategy (like GM) will have multiple divisions. More recently, firms (like Apple), which focus on design and product innovation but not component innovation, have internal capability for design and marketing but virtually no internal manufacturing capability.

We argue throughout this paper that strategy of a SEPB drives the structure of its website and the user interface, and not merely the structure of the firm. This is tested in our hypotheses.

\subsection{Theory of Newly Vulnerable Markets}

Newly vulnerable markets provide a theory to explain and understand changes in competition, in which new competitors are able to attack stronger incumbents, even in what look like mature industries. Digital platforms have changed the landscape of competition in a number of industries. SEPBs are by definition attacking markets in which the sharable assets are sufficiently broadly held by individual consumers.

The theory of newly vulnerable markets (NVM) [8] assesses whether an industry is vulnerable to new entrants. It builds on the theory of contestable markets [3], which posits that in monopolies or oligopolies that are under continuous threat of new entry, prices would be similar to perfect competition to eliminate the incentives of new entrants to enter the market because of zero profits. In contrast, oligopolies and monopolies that are not contestable do exhibit some degree of monopoly profits.

The theory of NVM depicts three conditions to determine market vulnerability. First, the market needs to have become newly easy to enter. This occurs when technological or regulatory changes reduce the entry barriers or when changes in consumer preferences weaken the competitive advantage of previously dominant firms. Cellphone service destroyed the old AT\&T because technology made it possible for new entrants to offer telephony service that could interact with all other phones regardless of their networks, while regulation made it possible for new firms to compete and, changes in consumer preferences made wireless telephony preferred over traditional landlines.

Second, the market must be attractive to attack. 
This implies the presence of a strong customer profitability gradient. This usually occurs when existing firms in an industry charge the same prices to all customers, even when customers differ substantially in willingness to pay for goods and services, or in their costs to serve. New entrants may target the most lucrative consumers, for example, the air travelers who are easiest to serve, or the banking customers who pay the highest finance charges each month because they maintain large unpaid balances.

Third, the market must be difficult to defend. This occurs when the incumbents experience barriers in changing their strategy to imitate the attacker's strategy.

The theory has been used in a variety of case studies, including the credit card industry [9] and the electronic travel distribution services [14]. Using NVM as a predictor of success, we investigate whether the markets, where the SEPBs have entered, are newly vulnerable, which would suggest that they have selected markets with a high probability of success.

\subsection{Theory of Resonance Marketing}

The theory of resonance marketing [6] explains that companies that now seek full differentiation and delight-based strategies are dependent upon the amount of information that customers have. In pure resonance marketing strategies, the information is provided by the environment, not by advertising, a condition called organic informedness [7]. We believe that SEPBs that follow a delight-based strategy, offering the individual user an ever-changing array of choices to satisfy every want or need, will need to provide that informedness themselves, since users will not be familiar, for example, with each individual property offered in Paris, or each amateur chef willing to prepare meals in Bangkok. The theory of resonance marketing suggests that the information-based structure of the SEPB website will need to follow the strategy selected for the business.

The theory of resonance marketing argues that the compromise discount creates an uncertainty discount in the presence of uncertainty about a product's true location in its product attribute space. The more uncertain a consumer is about a product that is ideal for him or her, the greater the range of unacceptable things the product could turn out to be, and thus, the more truly inferior locations that product could occupy. As uncertainty is reduced, also the range of inferior possibilities is reduced, and the smaller the expected compromise discount becomes. As the expected compromise discount decreases, consumers' willingness to pay eventually approaches the user's full valuation for any individual offering.
The work in resonance marketing that is most relevant to our current study shows that companies that want to follow a strategy based on delighting consumers must be aware of the uncertainty discount, and find mechanisms for reducing uncertainty [16, $12]$.

\subsection{Sharing Economy and Platforms}

The current understanding of the sharing economy, while very different from its original meaning in anthropology [22], typically refers to new assemblages or hybrids of economic modalities enabled by digital technologies and platforms. Habibi et al. [15] position sharing economy on a continuum between pure sharing and pure exchange. Sundararajan [24] defines the sharing economy as platforms engaged in crowdbased capitalism mixing gift and market economies. Likewise, Constantiou et al. [10] describe sharing economy platforms as mixing organizational with market coordination mechanisms. Sharing economy platforms are also viewed as multi-sided; they facilitate the transactions between different parties who would not necessarily transact otherwise [19]. These descriptions have much in common, but they have slight differences in emphasis that we need to clarify in order to understand the hypotheses and the SEPB classifications in this paper.

For the purpose of our research, we define SEPBs as platforms that facilitate the peer-to-peer allocation of temporary access to idle resources that are owned by individuals rather than corporations. In particular, our definition reflects the motivations and benefits generally ascribed to the sharing economy. First, the sharing economy allows consuming without buying, which enables consumption at lower costs [18]. Access over ownership refers to the temporary use of consumer goods without a transfer of ownership [23]. Second, peer-to-peer networks enable direct transactions between individuals and complement traditional business activities [2]; the sharing economy is different from prior business-to-consumer rental services. Peer-to-peer networks do not involve intermediaries and are based on trust and reputation [1]. Third, the allocation of idle resources allows for lowering costs of their access and also for more sustainable resource consumption $[23,25]$.

None of these three developments is new or exclusive to the sharing economy. However, with the rapid diffusion of digital infrastructures, platforms, and end-user devices, these developments have opened up new opportunities for value creation and commercial success. As demonstrated by Uber and Airbnb, SEPBs utilize such opportunities to their advantage as they enter mature markets and attack 
global and local incumbents alike [11].

The impact of sharing economy platforms on market dynamics is not yet fully understood. We can only draw on first, tentative insights and findings. For instance, Weber [26] suggests that incumbents offering high-cost goods may actually benefit from sharing economy markets, since sales of expensive items may be increased if the purchaser can recover some of the cost through shared access.

\section{Empirical Study}

Given the lack of empirical research and theoretical elaborations relating the strategy of sharing economy business to the structure of its online platform, we began our research following an exploratory case study research design. As noted by Yin, this is intended to develop propositions for future research [27]. Our case study research design and practice followed established guidelines for operations and IS research [13, 4] inasmuch as we 1) purposefully selected cases, which promised to reveal rich, in-depth data, 2) formulated research questions to focus our analysis, and 3) conducted within-case and 4) crosscase analysis. We present the findings of the case studies as hypotheses followed by the results of their statistical testing.

\subsection{Generation of Hypotheses}

As noted above, we started by using a small set of semantically rich case studies to develop theory followed by a set of hypotheses for the next stage of our study [17]. We studied Uber and Lyft in the ride hailing / ride sharing market; and Airbnb and Home Away as examples of temporary accommodations in the sharing economy, all of which are generally agreed to have been successful.

We observe that for these four SEPBs, business strategy drives platform structure and note that they have some attributes in common: they each follow one of the two classic strategies, defined as canonical strategies by Porter [21]. Uber and Lyft follow costbased strategies; and Airbnb and Home Away follow differentiation-based strategies. Of course, Uber and Lyft, Airbnb and Home Away, are neither products nor services; they are distribution channels for services. When we say that Uber and Lyft for costbased strategies we mean that the services they offer are less expensive than taxi services. When we say that Airbnb and Home Away follow differentiationbased strategies we mean that the services they offer seek to provide resonance and delight.

More interestingly, however, these four platforms adopt one of two very different structures. The two platforms that follow a cost-based strategy offer a simple website/app that provides the user with very little choice and thus require very little information. An Uber user is simply informed about his driver, his driver's car, his driver's identifying information, and enough information on the driver's rating to ensure a minimal level of trust and acceptance. Any further information, or any greater degree of user-interaction, would simply slow the operation of the ride matching service with no appreciable gain in user satisfaction. In contrast, the two platforms that follow a differentiation-based strategy offer robust information allowing the user to make a fully informed decision about which property to rent. The absence of information about location, size, condition, furnishings, accessories, internet access, and convenience to public transportation, would reduce potential guests' willingness to rent and reduce their willingness to pay. As we know from research on informed differentiation-based strategies [7], buyers don't just want the average of all reviews; they often want to examine the entire text of reviews. Differentiation-based strategies involve consumers who are seeking delight [9] and in those cases consumers must be presented with a sufficient amount of information in order to ensure that delight.

Thus, we note that differences in platform strategy result in differences in platform structure reflected in the way information and choice is offered on the respective website (for reasons of expediency, we subsume apps under the term "website"). This is the basis of our first set of hypotheses regarding strategy, structure, and information ( $\mathrm{H} 1 \mathrm{~A}-\mathrm{H} 1 \mathrm{C}$ and $\mathrm{H} 2$ ).

$\mathrm{H} 1 \mathrm{~A}$ - If the SEPB is following a differentiationbased strategy it will provide robust information on individual services or service providers.

Often this information is required to allow the users to choose which service or provider $\mathrm{s} / \mathrm{he}$ wishes, which will generate the highest degree of delight. Alternatively, when the differentiated service requires speedy execution, choice may not be possible. We expect differentiation-based strategies to require robust information, without needing to allow the users to make choices. This robust information is necessary to enable the user to believe that the offering selected for him or her will provide the required level of delight. Again, we refer to earlier work on the relationships among information, trust, and resonance marketing [6].

$\mathrm{H} 1 \mathrm{~B}$ - If the SEPB is following a cost-based strategy it will provide far less information on individual services or service providers and will not allow the users to choose which service or provider he wishes.

Most cost-based SEPBs do not seek to provide resonance and delight, do not need to allow users to 
make choices, and therefore do not need to provide the users with robust information.

$\mathrm{H} 1 \mathrm{C}$ - If the SEPB is following a cost-based strategy, but for goods and services that might be considered risky, it will provide robust information on individual services or service providers. Even when the platform will not allow the users to choose which service or provider s/he wishes, it will provide enough information for the user to make an informed decision about whether or not to proceed.

We generated hypothesis $\mathrm{H} 1 \mathrm{C}$ after considering the conditions under which we would allow a young child or an elderly person to be assigned to a ride service, and concluded that we would need far more information than for example Uber or Lyft currently provide before we would accept their selected car and driver, even if we did not require the ability to select the car and driver ourselves.

H1A through $\mathrm{H} 1 \mathrm{C}$ test for internal consistency, and a match between strategy and structure, for three separate types of service. $\mathrm{H} 2$ tests the entire data set for internal consistency.

$\mathrm{H} 2$ - Those SEPBs that were promising enough to capture the attention of the creator of our data set will have structures that match their strategy.

H1 suggests the ways in which strategy should drive structure. $\mathrm{H} 2$ suggests that websites considered promising to be included in the list of investment grade websites will indeed have strategy driving structure.

We also noticed that all four platform businesses that we studied in-depth (i.e. Uber, Lyft, Airbnb, Home Away) are attacking existing mature marketplaces. The markets for local transportation and for short term rental accommodations are both multibillion dollar industries, and both have existed in one form or another for centuries. Although all four SEPBs are attacking existing marketplaces for existing goods and services, we note that they all are attacking what we consider to be newly vulnerable markets. First, for the sharing economy to function, the goods in question must be sufficiently widely held for there to be enough in circulation for them to be shared. Additionally, if the platform is attacking a market for goods or services that are already widely held, the platform creators and their investors should want to have a strong reason for expecting success when attacking an existing market. The theory of NVM offers a sound and tested theory for predicting and explaining success.H1 and $\mathrm{H} 2$ led to the formulation of Hypotheses H3 through H5.

$\mathrm{H} 3$ - SEPBs will attempt to attack NVMs.

H4 - Successful SEPBs will be those that have attacked NVMs.

H5 - Successful SEPBs will be those that have attacked NVMs with structures that match their strategies.

\subsection{Analysis of a Database of SEPBs}

We analyzed a set of 104 SEPBs that were considered to be investment grade opportunities by Money Nomad. ${ }^{1}$ We used this curated list because it was large enough for statistical analyses, because the businesses included were considered high quality SEPBs, and because the SEPBs in the list were selected by someone outside our group, without awareness of our hypotheses. Together these conditions ensured that the websites were relevant to our study but were not selected because of conscious or unconscious biases, or by a desire to examine websites that supported our hypotheses.

We classified all 104 SEPBs on a number of dimensions, looking at the descriptions of the businesses in the article, the companies' own websites, the descriptions of the businesses available in the popular press and the investment community press, and Facebook and Yelp contents as available.

First, we checked to see if the business was still operating. A business that had been acquired by another sharing economy platform and merged was studied as part of the new business and not as an individual case. In contrast, a business that had been acquired by an unrelated business but was continuing to operate was included and studied in the context of its current operations. A business that had failed and closed was dropped from inclusion in our study, since we are trying to make predictions about the strategy and structure of successful SEPBs.

Next, we checked to see if we could consider the business as an SEPB. In line with our definition of SEPBs, we restricted our analysis to businesses that increased the size of the market by bringing new providers of goods and services into the marketplace, where those new providers were not professionals in the same sense as existing market participants. Using our definition, Uber and Lyft are both sharing economy businesses. An aggregator or an integrated search engine, that for instance functioned as a citywide dispatch service for all taxi companies, or created a travel marketplace like Orbitz, would not have been considered as an SEPB and would have been dropped from our study. We considered businesses that increased the size of a market by creating a spot market for access to individuals on a short-term basis, and defined these as participation economy businesses. As noted above, we decided to include participation economy businesses in our sample of SEPBs even if they did not involve sharing physical goods.

We then began classifying each identified company on several dimensions. We first determined if the business was cost-based or differentiation-based. 
Often this was clear from the websites of Money Nomad and the company itself. If necessary, we went to additional sources, but were always able to determine the principal strategy of the website and the business.

We next determined if the SEPB was attacking a newly vulnerable market or not. If there was a mature existing market, and if there was a customer profitability gradient that facilitated targeting specific customers online, and if there were structural reasons why incumbents could not immediately duplicate the strategies of successful attackers, then all necessary conditions of a newly vulnerable market were satisfied.

Third, we explored by examining the websites' user interfaces whether or not it was providing a limited or a robust set of information to its users. There is a continuum ranging from very little information to a description, photographs, maps, and testimonials, but all authors were able to agree on all of the classifications. (See Appendix A for an example of robust information.)

Fourth, we explored whether the website provided users with a single recommendation, which the user could accept or reject, or whether the website offered the user a range of choices. Also this classification required examining websites and their user interfaces.

The final classification we performed was determining how to assess a SEPB as successful or not. In most cases, this was the most complex part of our analysis. In the case of international giants like Uber and Airbnb the determination was easy. For small startups, there is no single definition of success of the SEPB. We agreed to consider a business successful if it had at least three successful rounds of venture capital or private equity financing; or, it had raised at least $\$ 1$ million in venture funds; or, it operated in at least three countries or at least 10 cities; or, it had at least 100,000 users or at least 10 thousand service providers; or, it was currently operating at a profit.

When we could not conclusively demonstrate a criterion as satisfied we needed to proceed as if the criterion was not satisfied. Even though this set of criteria might be considered as too inclusive, we found that a large subset of our database could be classified as successful.

The full data set we used, along with our classification of each of the entries and the reasons behind our classification, is available as Appendix B.

\section{SEPB Strategy and Structure}

Hypotheses $\mathrm{H} 1 \mathrm{~A}$ through $\mathrm{H} 1 \mathrm{C}$ and $\mathrm{H} 2$ test the internal consistency of the website. We examine each
SEPB website to determine if the information it displays is consistent with its choice as a provider of differentiated goods and services or as the provider of low cost goods and services. We also verify that the information it displays is consistent with the users' perceived risk profile associated with the goods and services the website offers. We divide the SEPBs based on their strategies simply into firms that compete as a low cost / low price provider, and firms that compete as a value-added provider of differentiated products and services $[21,20]$.

Table 1 shows a classification of the 67 surviving SEBPs, which constitute the sample we use for the statistical tests. Surviving SEBPs are those that are still independent businesses, are still operating at the time that we completed our analysis, and which are part of the sharing economy as we defined it (i.e. including participatory economy SEPBs). The first classification of the sample is according to both their strategy and whether or not users are empowered to make selections among alternative service providers.

Table 1. Descriptive statistics of surviving SEPBs

\begin{tabular}{|c|c|c|c|c|}
\hline & \multicolumn{3}{|c|}{ Strategy } \\
\hline & & Cost & Differentiation & Total \\
\hline \multirow{3}{*}{$\begin{array}{l}\text { Provision of } \\
\text { Choices to } \\
\text { Users }\end{array}$} & No Choice & $21(95,5 \%)$ & $1(4,5 \%)$ & 22 \\
\hline & Choice & $4(8,9 \%)$ & $41(91,1 \%)$ & 45 \\
\hline & Total & 25 & 42 & 67 \\
\hline
\end{tabular}

Table 2 displays the classification of SEPBs based on strategy and information provision. A chi-square test of independence was performed to examine the relation between SEPB's strategy and information provision to the platform participants. The result was significant $\left(\mathrm{X}^{2}(1, \mathrm{~N}=67)=40,226, \mathrm{p}<0,01\right)$ and supported H1A and H1B. SEBPs following a costbased strategy are less likely to provide robust information to the participants, while SEBPs following a differentiation-based strategy are more likely to provide robust information to the participants.

Table 2. SEPBs strategy and information provision

\begin{tabular}{|l|l|l|l|l|}
\hline \multicolumn{2}{|c|}{} & \multicolumn{3}{|c|}{ Strategy } \\
\cline { 2 - 5 } \multicolumn{2}{c|}{} & Cost & Differentiation & Total \\
\hline \multirow{3}{*}{$\begin{array}{l}\text { Information } \\
\text { Provision }\end{array}$} & $\begin{array}{l}\text { No robust } \\
\text { Information }\end{array}$ & $20(90,9 \%)$ & $2(9,1 \%)$ & 22 \\
\cline { 2 - 5 } & $\begin{array}{l}\text { Robust } \\
\text { Information }\end{array}$ & $5(11,1 \%)$ & $40(88,9 \%)$ & 45 \\
\cline { 2 - 5 } & Total & 25 & 42 & 67 \\
\hline
\end{tabular}

We realize that there are factors other than differentiation-based strategy that might require the provision of additional information. When considering extensions to Uber's basic ride service, letting a stranger delivery your restaurant meal seems even less risky than getting in the stranger's car, so we would expect the level of information about the driver on websites for food delivery to be similar to the level of 
information for the driver of your ride. In contrast, we might want a lot more information about the driver before we would feel comfortable letting him or her drive a small child to day care. Table 3 augments the analysis of table 2 and now includes an analysis of cost-based services where the user might perceive a higher degree of risk. We expect to see that the amount of information provided to users would be higher, whether or not users are allowed to select among individual service providers.

The result was significant $\left(\mathrm{X}^{2}(2, \mathrm{~N}=67)=\right.$ $43,249, \mathrm{p}<.01$ ) and supported $\mathrm{H} 1 \mathrm{C}$ and $\mathrm{H} 2$.

Table 3. SEPBs refined strategy and information provision

\begin{tabular}{|c|c|c|c|c|c|}
\hline & \multicolumn{4}{|c|}{ Strategy } \\
\hline & & Cost & $\begin{array}{l}\text { Cost and } \\
\text { risky } \\
\text { services }\end{array}$ & $\begin{array}{l}\text { Differentiati } \\
\text { on }\end{array}$ & Total \\
\hline \multirow[t]{3}{*}{$\begin{array}{l}\text { Information } \\
\text { Provision }\end{array}$} & $\begin{array}{l}\text { No robust } \\
\text { Information }\end{array}$ & $\begin{array}{l}20 \\
(90,9 \%)\end{array}$ & $0(0 \%)$ & $2(9,1 \%)$ & 22 \\
\hline & $\begin{array}{l}\text { Robust } \\
\text { Information }\end{array}$ & $\begin{array}{l}4 \\
(8,9 \%)\end{array}$ & $1(2,2 \%)$ & $40(88,9 \%)$ & 45 \\
\hline & Total & 24 & 1 & 42 & 67 \\
\hline
\end{tabular}

SEPBs following a cost-based strategy are less likely to provide robust information to the participants in the absence of risk to the user. In contrast, SEPBs that follow a differentiation-based strategy and those that follow a cost-based strategy that users perceive as involving risk are both more likely to provide robust information to the participants.

\section{SEPB as an Attack on Newly Vulnerable Markets}

The three hypotheses (H3-H5) address the extent to which the business is attacking a marketplace in which there should be a rational expectation for success.

We use the theory of NVM as a plausible basis for expecting success when entering a market for goods and services that have existed for decades, or even for centuries. Newly vulnerable markets require three attributes, as described above. First, we find that the principal purpose of an SEPB platform is to exploit a new technological opportunity that made a market newly easy to enter.

The principal function of markets is pooling buyers and sellers with sufficient liquidity to allow transactions to match and trades to occur. This in turn allows markets to determine market clearing prices. Historically markets existed in a fixed place, so that buyers and sellers could congregate to trade, and; they were often for relatively simple tradeable items, which could therefore be traded without the need for extensive physical inspection.

Increasingly, online markets exist where both of these attributes are absent. When guests rent a space via Airbnb they are often time zones and even oceans removed from the renters who provide their space; they are not meeting in a single space. Likewise, when users hail a ride from Uber or Lyft they are seldom able to see their driver or the vehicle; no physical inspection is possible beforehand. Since both historical constraints can be removed, this suggests that there are now markets that are newly easy to enter.

However, newly vulnerable markets must also be attractive to attack. This usually occurs when there is a customer profitable gradient, when some customers are demonstrably more profitable to serve and these customers can be identified, targeted, and captured as customers for the new attacker.

The existence of the profitability gradient for each of these SEPB's customer-bases is more complicated to demonstrate. For Uber X, we were able to show that these customers are profitable because drivers do not have to wait or cruise, because the customers would pay higher prices in periods of peak demand, and because drivers do not require more expensive commercial insurance or commercial licenses. For Airbnb we were able to show that these customers are more profitable because they do not require the expensive infrastructure of hotels, or in fact that they were not being served at all.

This was also true of those examples in our larger data set where we believed that the SEPB was attacking a newly vulnerable market. For example, the distribution of alcoholic beverages is a market that has existed for millennia, but Saucey serves customers (www.saucey.com/) who are willing to pay for effortless and immediate delivery of alcohol. Similarly, Just Park (www.justpark.com/) serves customers willing to pay for effortless and immediate access to parking space.

Finally, if SEPBs are to be seen as an attack on newly vulnerable markets we then need to demonstrate that the markets they are targeting are difficult for the established market participants to defend. This was easy to demonstrate for Uber and Airbnb. Taxi companies are prohibited from adopting the lower cost structure of Uber, and they cannot match supply and demand by adjusting prices or by bringing a large number of additional vehicles to match temporary supply shortages. Likewise, hotels are prohibited by regulation and zoning restrictions from matching the strategy of Airbnb hosts.

This was also true of those examples in our larger data set where we believed that the SEPB was attacking a newly vulnerable market.

We consider two examples from our SEPB startup database. Consider Postmates (www.postmates.com/), which attacks postal and parcel delivery companies, because regulations make it impossible for them to 
match supply and demand by adjusting prices, and because they cannot bring a large number of additional employees to match temporary supply shortages. Similarly, LawTrades (www.lawtrades.com) attacks law firms, which cannot adjust their personnel resources to address temporary supply shortage or cannot reduce the service prices since the firms have fixed costs.

Thus, our assessment of Uber and Airbnb is consistent with our proposition that SEPBs attack newly vulnerable markets, and consistent with $\mathrm{H} 3$ through H4. More importantly, we were able to find support for $\mathrm{H} 3$ through $\mathrm{H} 4$ in our larger dataset.

We explore the 44 (of the 67 in the sample) that we identified were attacking NVMs, to see the extent to which strategy determines information disclosure. Only one of them involved a risky decision, and that site did provide robust information. However, sample of one is too small for statistical testing, and we drop it from further analysis.

Table 4 indicates which followed cost-based strategies and which followed differentiation-based strategies. Likewise, the table indicates which had structures that provided complete and robust information to enable consumer choice and which did not. We expect that websites that offer products and services that require an extreme level of trust will not observe that same simple provision of limited information that other cost-focused websites are able to deploy, but without a larger sample we cannot test this.

Table 4. SEBPs which attack a NVM

\begin{tabular}{|c|c|c|c|c|}
\hline & \multicolumn{3}{|c|}{ Strategy } \\
\hline & & Cost & Differentiation & Total \\
\hline \multirow[t]{3}{*}{$\begin{array}{l}\text { Information } \\
\text { Provision }\end{array}$} & $\begin{array}{l}\text { No robust } \\
\text { Information }\end{array}$ & $15(88,2 \%)$ & $2(11,8 \%)$ & 17 \\
\hline & \begin{tabular}{|l|} 
Robust \\
Information
\end{tabular} & $1(3,7 \%)$ & $26(96,3 \%)$ & 27 \\
\hline & Total & 16 & 28 & 44 \\
\hline
\end{tabular}

Table 5 shows which of the 56 SEPB websites that we considered successful were attacking newly vulnerable markets. A chi-square test of independence was performed to examine the relation between SEPB's success and attack of a NVM. The result was significant $\left(\mathrm{X}^{2}(1, \mathrm{~N}=67)=5,014, \mathrm{p}<0.05\right)$, and supported H4. SEPBs which are considered successful are more likely to have attacked a NVM, while SEPBs which are not consider successful a less likely to have attacked a NVM.

Table 5. SEBPs based on success and whether attacking a NVM

\begin{tabular}{|l|l|l|l|l|}
\hline \multicolumn{2}{|c|}{} & \multicolumn{3}{l}{ Success } \\
\cline { 3 - 5 } \multicolumn{2}{|c|}{} & No & Yes & Total \\
\hline \multirow{3}{*}{ NVM } & No & 7 & 16 & 23 \\
\cline { 2 - 5 } & Yes & 4 & 40 & 44 \\
\cline { 2 - 5 } & Total & 11 & 56 & 67 \\
\hline
\end{tabular}

We should not be surprised to observe a lack of perfect correlation between matching strategy and structure and achieving initial success. Companies that create new markets can succeed as well, without attacking an existing newly vulnerable markets social media is a prime example of this. Companies that create markets that do not appear vulnerable can still succeed because of superior products. Likewise, companies that initially appear successful when attacking stable markets may look good briefly and then collapse - many of the dot-com failures exemplify this well.

Finally, we combine the internal consistency checks (H1A-H1C and H2) with the checks for attacking a newly vulnerable market (H3 and H4). H5 examines which successful SEPBs were attacking a newly vulnerable market and had strategy related to structure in the way we predicted.

Table 6 shows our classification of the 40 SEPBs that were attacking newly vulnerable markets. The table indicates which followed cost-based strategies and which followed differentiation-based strategies. Likewise, the table indicates which had structures that provided complete and robust information to enable consumer choice and which did not.

Table 6. SEBPs considered successful

\begin{tabular}{|l|l|l|l|l|}
\hline \multirow{2}{*}{} & \multicolumn{3}{|c|}{ Strategy } \\
\cline { 2 - 5 } \multicolumn{2}{|c|}{} & Cost & Differentiation & Total \\
\hline \multirow{3}{*}{$\begin{array}{l}\text { Information } \\
\text { Provision }\end{array}$} & $\begin{array}{l}\text { No robust } \\
\text { Information }\end{array}$ & $14(87,5 \%)$ & $2(12,5 \%)$ & 16 \\
\cline { 2 - 5 } & $\begin{array}{l}\text { Robust } \\
\text { Information }\end{array}$ & $1(4,2 \%)$ & $23(95,8 \%)$ & 24 \\
\cline { 2 - 5 } & Total & 15 & 25 & 40 \\
\hline
\end{tabular}

A chi-square test of independence was performed to examine the relation between SEPB's strategy and information provision to the platform participants. The result was significant $\left(\mathrm{X}^{2}(1, \mathrm{~N}=40)=28,444, \mathrm{p}\right.$ $<0,01)$ and supported H5. Successful SEPBs that attack an NVM and that follow a cost-based strategy are less likely to provide robust information to their participants, while successful SEBPs that attack an NVM and that follow a differentiation-based strategy are more likely to provide robust information to the participants.

\section{Conclusions}

\subsection{Limitations of the Current Study}

Our data sets are small. We are currently developing a larger data set of SEPBs for which we can determine strategy and structure, and for which we can assess success with a reasonable degree of accuracy. This data set is being prepared by a research assistant with no other responsibility for the project. She is selecting as many SEPBs as she can locate, without preselecting 
or prescreening them using any criteria related to our hypotheses. This represents a first, but critical step, towards reducing selection bias in our study of an expanded sample. Recall that our data set in this initial sample was selected by third parties, to ensure an absence of selection bias.

This larger data set will also be more comprehensive, and will capture data like the age of a website. This will be useful in subsequent analyses, such as those that allow us to test whether matching strategy to structure is a characteristic of all websites, or rather is a characteristic of websites that survive.

\subsection{Managerial Implications}

If our results are robust and supported by future studies, they can provide guidance to incumbents who need to prepare for attack from SEPBs and who need guidance on how to prepare for attack. They can also provide guidance to entrepreneurs considering opportunities for new businesses and venture capitalists and private equity funds considering which opportunities are indeed promising enough to justify investment.

More precisely, we are saying two things here. If our results are supported by future studies then innovators considering launching an SEPB should carefully match the structure of the website to the strategy behind the selection of candidates for the service being offered. Websites in support of resonance strategies should provide information-rich interfaces, while those in support of efficiency should provide less information. We called this internal consistency. Moreover, since virtually all services in the sharing economy have an established traditional counter-part, innovators considering launching an SEPB should have a reason for anticipating success; that is, the established market they are attacking should be newly vulnerable. We termed this external consistency.

These implications derive directly from out contribution to theory, below.

\subsection{Contributions to Theory}

The first two hypotheses make a small contribution to theory and they suggest that those websites that met the Money Nomad list of promising SEPBs illustrated an internal consistency. For those websites, strategy drives structure. The third and fourth hypotheses make an additional contribution. Since by definition sharing economy businesses share existing goods and services, they are likewise almost by definition attacking existing markets. Their designers and investors should have a reasonable theoretical basis to expect successful attack. The theory of NVM provides one such theory for predicting successful attack.
Hypotheses 3 and 4 confirm that promising SEPBs are not only internally consistent with strategy matching structure, but they are also externally consistent with strategy matching existing market conditions.

Finally, the fifth hypothesis may generate the most interesting results. Hypothesis 5 argues that successful SEPBs will be those that have attacked NVMs with structures that match their strategies. Our findings show that successful websites overwhelmingly exhibit internal and external consistency. Strategy of the firm drives the function of the website, which in turn drives the structure of the website and of the user interface. In brief, in a different context from Chandler's [5], and at the level of product design rather than organizational structure, we find that structure is driven by strategy. Strategy is consistent with marketplace economics.

What is significant is that we have developed simple tests for internal and external consistency. We show that not only are successful websites consistent with their marketplace (externally consistent) they are also internally consistent, in that design matches strategy. Successful websites satisfy both of our conditions for consistency.

\subsection{Suggestions for Future Research}

The most important suggestion is to repeat the research with a larger data set. This work has already started, with efforts to locate other curated lists of promising SEPBs, and to locate our own SEPBs that we consider promising. As before, an essential condition is that we avoid contaminating our data set through bias in our selection criteria, which would result in our including principally SEPBs whose strategy and structure are consistent with our hypotheses.

Additionally, researchers would probably want to repeat the analyses several years later, when there will be a larger number of SEPBs for which success can unambiguously be demonstrated. It would also be interesting to see after a couple of years how many changes we would have in our classification of the successful websites on our list.

When the research is conducted at a later time, two additional studies will be possible. First, it is reasonable to expect that the sharing economy marketplace will have become much more crowded and much more competitive. It is likely that the simple binary classification we used here - cost / efficiency based strategies and differentiation / resonance strategies, will have ceased to be fully effective. More complex, hybrid strategies will probably have been adopted, and a more complex set of hypotheses will be required to 
examine the more complex relationship between strategy and structure that will have emerged. Additionally, some SEPBs will have failed, and we will be able to examine both surviving and failed websites to ascertain whether lack of internal or external consistency was a significant contributor to website failure.

Finally, other definitions of internal and external consistency may be useful in testing for different elements of website design or of interface design. These may be equally valid and may produce even stronger results or more useful insights.

\section{References}

[1] O. Abramova, T. Shavanova, A. Fuhrer, H. Krasnova and P. Buxmann, "Understanding the sharing economy: The role of response to negative reviews in the peer-to-peer accommodation sharing network", 23rd European Conference on Information Systems, Münster, Germany, 2015.

[2] M. Andersson, A. Hjalmarsson and M. Avital, "Peer-topeer service sharing platforms: Driving share and share alike on a mass-scale", 34th International Conference on Information Systems, Milan, Italy, 2013.

[3] W. J. Baumol, Contestable markets: An uprising in the theory of industry structure, MIT Press, Cambridge, MA, 1986.

[4] I. Benbasat, D. K. Goldstein and M. Mead, "The case research strategy in studies of information systems", MIS Quarterly, 11 (1987), pp. 369-386.

[5] A. D. Chandler, Strategy and structure: Chapters in the history of the industrial enterprise, MIT Press, Cambridge, MA, 1962.

[6] E. K. Clemons, "How information changes consumer behavior and how consumer behavior determines corporate strategy", Journal of Management Information Systems, 25 (2008), pp. 13-40.

[7] E. K. Clemons and G. Gao, "Consumer informedness and diverse consumer purchasing behaviors: Traditional massmarket, trading down, and trading out into the long tail", Electronic Commerce Research and Applications, 7 (2008), pp. 3-17.

[8] E. K. Clemons, B. Gu and K. R. Lang, "Newly vulnerable markets in an age of pure information products: An analysis of online music and online news", Journal of Management Information Systems, 19 (2002), pp. 17-41.

[9] E. K. Clemons and M. E. Thatcher, "Capital One Financial and a decade of experience with newly vulnerable markets: Some propositions concerning the competitive advantage of new entrants", Journal of Strategic Information Systems, 17 (2008), pp. 179-189.

[10] I. Constantiou, A. Marton and V. K. Tuunainen, "Four models of sharing economy platforms", MIS Quarterly Executive, 16 (2017), pp. 231-251.

[11] M. A. Cusumano, "How traditional firms must compete in the sharing economy", Communications of the ACM, 58

\footnotetext{
1 “100 Sharing Economy Apps and Websites You Don't Want to
} Miss", at https://www.moneynomad.com/100-sharing-economy-
(2014), pp. 32-34.

[12] D. Dey and A. Lahiri, "Versioning: Go vertical in a horizontal market?", Journal of Management Information Systems, 33 (2016), pp. 546-572.

[13] K. M. Eisenhardt, "Building theories from case study research", The Academy of Management Review, 14 (1989), pp. 532-550.

[14] N. F. Granados, R. J. Kauffman and B. King, "How has electronic travel distribution been transformed? A test of the theory of newly vulnerable markets", Journal of Management Information Systems, 25 (2008), pp. 73-96.

[15] M. R. Habibi, A. Davidson and M. Laroche, "What managers should know about the sharing economy", Business Horizons, 60 (2017), pp. 113-121.

[16] P. M. Markopoulos and E. K. Clemons, "Reducing buyers' uncertainty about taste-related product attributes", Journal of Management Information Systems, 30 (2013), pp. 269-299.

[17] A. Marton, Purposive selection and the quality of qualitative IS research, 34th International Conference on Information Systems, Milan, IT, 2013.

[18] A. Marton, I. Constantiou and G. Lagoudakos, "Openness and legitimacy building in the sharing economy: An exploratory case study about CouchSurfing", 50th Hawaii International Conference on System Sciences, Waikoloa, HI, 2017.

[19] G. Parker, S. P. Choudary and M. Van Alstyne, Platform revolution: How networked markets are transforming the economy - And how to make them work for you, W. W. Norton, New York, NY, 2016.

[20] M. E. Porter, Competitive advantage: Creating and sustaining superior performance, Free Press, Now York, NY, 1985.

[21] M. E. Porter, Competitive strategy: Techniques for analyzing industries and competitors, Free Press, Now York, NY, 1980.

[22] F. Rudmin, "The consumer science of sharing: A discussant's observations", Journal of the Association for Consumer Research, 1 (2016), pp. 198-209.

[23] A. Sach, "IT-user-aligned business model innovation (ITUA) in the sharing economy: A dynamic capabilities perspective", 23rd European Conference on Information Systems, Münster, Germany, 2015.

[24] A. Sundararajan, The sharing economy: The end of employment and the rise of crowd-based capitalism, MIT Press, Cambridge, MA, 2016.

[25] R. T. Watson, M.-C. Boudreau, A. J. Chen and H. Sepúlveda, "Green projects: An information drives analysis of four cases", The Journal of Strategic Information Systems, 20 (2011), pp. 55-62.

[26] T. A. Weber, "Product pricing in a peer-to-peer economy", Journal of Management Information Systems, 33 (2016), pp. 573-596.

[27] R. K. Yin, Case study research: Design and methods, Sage, Thousand Oaks, CA, 2003.

apps-websites/ last accessed 05/21/2018. There were indeed 104 websites included this list of 100 apps and websites. 